\title{
Latent tuberculosis infection: An overview
}

\author{
S Kiazyk ${ }^{1,2 *}$, TB Ball ${ }^{1,2,3}$
}

\begin{abstract}
Latent tuberculosis infection (LTBI) is defined as a state of persistent immune response to stimulation by Mycobacterium tuberculosis antigens without evidence of clinically manifested active tuberculosis (TB) disease. Individuals with LTBI represent a reservoir for active TB cases. The detection and management of LTBI is now a key component of the World Health Organization's End TB Strategy and the Government of Canada's federal framework for action on TB prevention and control. This is because people with LTBI can progress to active TB or undergo reactivation, a risk that is greatly increased in those with immunocompromising conditions. This overview provides a summary of LTBI and reactivation risk, as well as the recent advances in the diagnosis and treatment of LTBI.
\end{abstract}

Suggested citation: Kiazyk S, Ball TB. Latent tuberculosis infection: An overview. Can Commun Dis Rep. 2017;43(3):62-6. https://doi.org/10.14745/ccdr.v43i34a01

\section{Introduction}

Tuberculosis (TB) is a leading cause of death worldwide, with 10.4 million cases and 1.8 million deaths in 2015 (1). Infected individuals are classified as either having latent tuberculosis infection (LTBI), an asymptomatic clinical state that is not transmissible, or active TB disease, characterized by the presence of clinical symptoms arising from infection that can occur in multiple organs. While Mycobacterium tuberculosis, the bacterium that causes TB, can infect many parts of the body, pulmonary TB is primarily the transmissible form. Our understanding of $M$. tuberculosis infection as a clear binary condition that is either active or latent has recently shifted, and the more modern view treats infection as a spectrum of disease states (2).

The World Health Organization's (WHO) End TB Strategy has set the goal to reduce TB incidence globally by $90 \%$ and TB deaths by $95 \%$ by 2035 (3). While active TB case detection has been the cornerstone of the public health response to TB, modelling suggests that in order to reach these ambitious targets, reducing the LTBI reservoir through preventative therapy is essential $(3,4)$. Preventing the progression of LTBI to active TB disease is an important public health goal that can substantially reduce TB transmission. A key part of the End TB Strategy is targeted treatment of those infected and who are at risk for progression to active TB disease.

The objective of this paper is to summarize what we know about LTBI, including the risk factors for reactivation, recent advances in diagnosis and treatment, and next steps in advancing the global plans for TB elimination.

\section{Latent tuberculosis infection and reactivation}

The WHO defines LTBI as a state of persistent immune response to stimulation by $M$. tuberculosis antigens without evidence of clinically manifested active TB (5). According to recent estimates, approximately one-quarter of the global population is infected with LTBI (6). The duration of latency is variable, and healthy individuals can harbour LTBI for a lifetime. In a small fraction ( $5 \%-15 \%)$, reactivation occurs, often within the first 2 to 5 years following infection $(7,8)$. Reactivation is the process by which a subclinical latent infection transitions into active TB disease. Thus, individuals with LTBI represent a major reservoir for new active TB cases (9).

The understanding of the underlying reasons for LTBI reactivation is incomplete, but it does include bacterial, host and environmental factors (10). While the lifetime risk for reactivation among otherwise healthy individuals with documented LTBI is quoted as approximately $5 \%$ to $15 \%(7,8)$, various comorbidities and risk factors are associated with increased risk and hence elevated rates of developing active TB. The most potent risk factor is human immunodeficiency virus (HIV) infection. Those with HIV and latent TB co-infection have more than a 100-fold increased risk of developing active TB disease (11). Even after successful antiretroviral therapy, the risk remains significantly elevated $(12,13)$. Other comorbidities and conditions associated with LTBI reactivation are categorized as high, moderate, slightly increased, low and very low risk, depending on their associated risk factors (14). In the high-risk category are patients with chronic renal failure requiring hemodialysis (15), transplant patients on immune suppressants (16) and patients with silicosis (17), among others. At moderate risk are patients treated with tumour necrosis factor alpha (TNF- $\alpha$ ) inhibitors (used for many autoimmune and inflammatory conditions) (18) or glucocorticoids (19), those with diabetes (all types) and recently infected children under the age of four (20). Those who abuse alcohol (21), smoke cigarettes (22) or are underweight or malnourished (23) are at slightly increased risk for LTBI reactivation. TB incidence is higher among these groups than within the general population (14). A commonality among the majority of these conditions leading to increased reactivation risk is suppressed immunity. 


\section{LTBI treatment}

TB reactivation rates can be substantially reduced by up to $90 \%$, if LTBI patients take preventative therapy $(24,25)$. The major indications for LTBI therapy are recent infection or the presence of other factors for increased risk for TB reactivation as noted above. The standard treatment regimen is nine months of daily self-administered isoniazid (INH9), although a 6-month course is also acceptable but not preferred due to reduced efficacy (14). Due to the length of treatment, and hepatotoxicity-related side effects, adherence is a major issue affecting therapy completion. The 3- to 4-month daily isoniazid plus rifampin regimen is authorized for use in Canada as an alternative, as is the 4-month daily rifampin regimen (14). Recently, a 12-dose once-weekly regimen of isoniazid plus rifapentine (commonly known as 3HP), administered by directly observed therapy, has been shown to be as effective as the standard INH9, and has also resulted in reduced hepatotoxicity and higher compliance rates (26). Currently rifapentine is not authorized for use in Canada and is only available through Health Canada's Special Access Program. For more information on the $3 \mathrm{HP}$ regimen, see Pease et al. in this issue (27).

\section{LTBI diagnostics}

The effective delivery of preventative therapies relies on sensitive and accurate LTBI diagnosis to guide treatment delivery. While bacterial culture is the gold standard for the diagnosis of an active infection, there remains no such standard for the detection of LTBI (28). Since detection of the actual pathogen is not possible, LTBI is detected by measuring immune responses to M. tuberculosis antigens.

Two tests currently measure immune responses to $M$. tuberculosis antigens: the tuberculin skin test (TST), which dates back over 100 years, and the more recent interferon-gamma release assay (IGRA) $(28,29)$. The TST evaluates cell-mediated immunity and consists of the intradermal injection of a small amount of purified protein derivative from the $M$. tuberculosis bacteria. The test requires two patient visits with a 48-72 hour interval between the administration and reading of the test. It is open to considerable variation in the interpretation of results.

The IGRA is a whole blood-based in vitro assay that measures the production of interferon-gamma by immune cells in response to $M$. tuberculosis antigen stimulation. The test does not require that the patient return to the lab and can be completed in 24 hours, but it does require greater laboratory infrastructure and technical capacity, which means it is more expensive. The specificity of the IGRA is superior to the TST as it utilizes antigens found only in M. tuberculosis, thereby eliminating cross-reactivity with the Bacille Calmette-Guerin (BCG) vaccine strain that is still routinely used in many countries, including Canada in some high TB-burden northern communities $(14,28)$. There are two IGRA platforms currently available in Canada. The QuantiFERON-Gold In-Tube test is based on an enzyme-linked immunosorbent assay (ELISA) for the detection of interferon-gamma production in separated plasma. The T.SPOT.TB test is an enzyme-linked immunospot (ELISPOT) assay based on the enumeration of interferon-gamma producing immune cells; it requires lymphocyte separation, stimulation and culture.

The Canadian Tuberculosis Standards recommend the use of either TST or IGRA for LTBI diagnosis (14). Only those who would benefit from treatment, including those at high risk for reactivation, should be tested. The IGRA is the preferred test in individuals who have had a BCG vaccine after infancy or in groups with poor return rates for TST reading (14). The TST is recommended if repeat testing is planned (14). Neither test should be used to screen those at low risk for infection or progression, to diagnose active TB or to monitor TB treatment response.

Because the TST and IGRA rely on the detection of a specific immune response, both tests have reduced sensitivity among immunocompromised populations, leading to high levels of false-negative results. This includes those who are HIV infected, where test sensitivity decreases with loss of CD4 T cell counts $(30,31)$, and patients with end stage renal disease (32). Unfortunately, it is these same groups that have the highest risk for $L T B I$ reactivation and require accurate testing and treatment.

\section{New LTBI diagnostics}

The development of new diagnostics for LTBI has been slow, but some recent advances include a skin test, C-Tb, that utilizes M. tuberculosis-specific antigens similar to those used in the IGRA assays, eliminating cross-reactivity with the BCG vaccine while maintaining sensitivity of the existing TST assay (33). The latest generation of the Quantiferon test has also been recently released. The QuantiFERON-TB Gold Plus assay incorporates new antigens designed to increase test sensitivity among immunocompromised groups, including people living with HIV. The initial independent evaluations, however, have shown this new test to have minimal increased sensitivity (34). Variations of the IGRA test that utilize alternate immune readouts in response to TB antigen stimulation are also being explored. One such readout is the cytokine IP-10, produced at much higher levels than interferon-gamma. Use of such a readout could both increase test sensitivity, particularly in immunocompromised groups, as well as reduce time to detection, bringing the test closer to true point of care testing (35).

In addition to sensitivity issues, neither the TST nor the IGRA can accurately distinguish active TB disease from LTBI, and neither can predict LTBI reactivation $(29,35,36)$. There is a need for advancements to be made in the LTBI diagnostics field to develop improved tools for diagnosing LTBI and predicting $\mathrm{LTBI}$ reactivation. A more sophisticated understanding of the immunology of LTBI and the underlying factors associated with progression to active disease is critical to identifying new biomarkers or immune signatures that will form the basis of new LTBI diagnostics and tools to monitor the success of therapeutic regimens. A promising advance in this direction is a 16-gene messenger RNA transcript-signature in blood that predicts subsequent disease progression and is able to distinguish between latent infection and active TB disease (37). In addition, it seems to be associated with bacterial burden as the immune transcript-signature was lost following TB treatment. Development of diagnostic tests that can identify those most at risk for reactivation and development of TB disease could help 
guide interventional strategies to target those most at risk for reactivation and therefore most in need of preventative therapy.

\section{The strategy to eliminate tuberculosis}

For countries such as Canada who have already reached the End TB target milestones ( $<100$ TB cases/million), an action framework was created by WHO to reach TB elimination targets (<1 TB case/million) by 2050 (38). This framework was designed recognizing that in low incidence countries, TB transmission is infrequent within the general population, and aside from occasional outbreaks, most cases of active TB are due to reactivation of $\operatorname{LTBI}(9,39)$.

In 2015, the WHO published guidelines on testing, treating and managing LTBI in infected individuals with the highest likelihood of progression to active disease (5). These guidelines call for a targeted public health approach that includes screening of select groups at high risk for LTBI reactivation coupled with preventative treatment in those who will most benefit from it $(40,41)$. Target groups include people living with HIV, adult and child contacts of pulmonary TB cases, patients initiating anti-tumour necrosis factor treatment, patients receiving dialysis, patients preparing for transplantation and patients with silicosis. Other vulnerable and/or hard-to-reach groups with a higher incidence of TB disease include those in correctional facilities, those with drug and alcohol addictions, people dealing with homelessness, residents of long-term care facilities, Indigenous populations, and migrants from countries with a high TB burden. For these high-risk groups, systematic testing is recommended in countries where resources are available. Both the IGRA and TST are recommended tools for screening, and chest radiography should be performed prior to initiating LTBI therapy to rule out active TB disease. Patients taking LTBI treatment should also be monitored regularly for potential adverse side effects (5).

Elements of the WHO guidelines are being implemented in Canada, and the identification and treatment of LTBI among those at high risk for developing active TB disease is a key area of focus as outlined in the Government of Canada's federal framework for action on TB prevention and control (42). The Canadian Tuberculosis Standards, developed by the Canadian Thoracic Society and the Public Health Agency of Canada, recommend the targeted screening of groups identified as at increased risk for LTBI reactivation, similar to those groups outlined in the WHO LTBI management guidelines (14). As these targeted screening and treatment approaches are likely to be led mainly by primary care providers, it is important that physicians are informed of LTBI screening and management policies in order to recognize risk factors. The most important factors to consider when selecting people as suitable candidates for LTBI screening and treatment are their risk of prior TB exposure and for reactivation balanced against the risk for hepatotoxicity, and the likelihood of treatment completion.

\section{Conclusion}

The reactivation of TB from untreated LTBI is a major source of new active TB infections and transmission. It accounts for the majority of new tuberculosis cases in countries where the incidence of tuberculosis is low, such as Canada. In order to meet TB elimination goals, targeted LTBI testing and treatment of marginalized and hard-to-access groups and those with high risk for TB reactivation is a priority. Shorter and efficacious preventative treatment regimens, more sensitive LTBI diagnostics and novel tests to identify those individuals at the highest risk for TB reactivation will all help to reach the TB elimination goals.

\section{Conflict of Interest}

None.

\section{Contributions}

SK: conceptualization, preparation of original draft, review and editing. TBB: conceptualization, review and editing.

\section{References}

1. World Health Organization. Global tuberculosis report 2016. Geneva: WHO; 2016. Available from: http://www.who.int/tb/ publications/global_report/en/.

2. Barry CE, 3rd, Boshoff HI, Dartois V, Dick T, Ehrt S, Flynn J, Schnappinger D, Wilkinson RJ, Young D. The spectrum of latent tuberculosis: rethinking the biology and intervention strategies. Nat Rev Microbiol. 2009;7:845-55.

3. World Health Organization. The End TB Strategy. Geneva: WHO; 2014.

4. Dye C, Glaziou P, Floyd K, Raviglione M. Prospects for tuberculosis elimination. Annu Rev Public Health. 2013;34:271-86. doi; 10.1146/annurevpublhealth-031912-114431.

5. World Health Organization. Guidelines on the management of latent tuberculosis infection. Geneva: WHO; 2015.

Available from: http://www.who.int/tb/publications/latenttuberculosis-infection/en/.

6. Houben RM, Dodd PJ. The global burden of latent tuberculosis infection: a re-estimation using mathematical modelling. PLoS Med. 2016;13: e1002152.

7. Comstock GW, Livesay VT, Woolpert SF. The prognosis of a positive tuberculin reaction in childhood and adolescence. Am J Epidemiol. 1974;99:131-8.

8. Vynnycky E, Fine PE. The natural history of tuberculosis: the implications of age-dependent risks of disease and the role of reinfection. Epidemiol Infect. 1997;119:183-201.

9. Shea KM, Kammerer JS, Winston CA, Navin TR, Horsburgh CR Jr. Estimated rate of reactivation of latent tuberculosis infection in the United States, overall and by population subgroup. Am J Epidemiol. 2014;179:216-25.

10. Getahun H, Matteelli A, Chaisson RE, Raviglione M. Latent Mycobacterium tuberculosis infection. N Engl J Med. 2015;372:2127-35.

11. Selwyn PA, Hartel D, Lewis VA, Schoenbaum EE, Vermund $\mathrm{SH}$, Klein RS, Walker AT, Friedland GH. A prospective study of the risk of tuberculosis among intravenous drug users 
with human immunodeficiency virus infection. N Engl J Med. 1989;320:545-50.

12. Moore D, Liechty C, Ekwaru P, Were W, Mwima G, Solberg P, Rutherford R, Mermin J. Prevalence, incidence and mortality associated with tuberculosis in HIV-infected patients initiating antiretroviral therapy in rural Uganda. AIDS. 2007;21:713-9.

13. Lawn SD, Churchyard G. Epidemiology of HIV-associated tuberculosis. Curr Opin HIV AIDS. 2009;4(4):325-33.

14. Canadian Tuberculosis Standards, 7th ed. Ottawa: Public Health Agency of Canada; 2014. p. 1-468. Available from: http://www.phac-aspc.gc.ca/tbpc-latb/pubs/tb-canada-7/ index-eng.php.

15. Christopoulos Al, Diamantopoulos AA, Dimopoulos PA, Goumenos DS, Barbalias GA. Risk factors for tuberculosis in dialysis patients: a prospective multi-center clinical trial. BMC Nephrol. 2009;10:36.

16. Sidhu A, Verma G, Humar A, Kumar D. Outcome of latent tuberculosis infection in solid organ transplant recipients over a 10-year period. Transplantation. 2014;98:671-5.

17. Rees D, Murray J. Silica, silicosis and tuberculosis. Int J Tuberc Lung D. 2007;11(5):474-84.

18. Keane J, Bresnihan B. Tuberculosis reactivation during immunosuppressive therapy in rheumatic diseases: diagnostic and therapeutic strategies. Curr Opin Rheumatology. 2008;20:443-9.

19. Jick SS, Lieberman ES, Rahman MU, Choi HK. Glucocorticoid use, other associated factors, and the risk of tuberculosis. Arthritis Rheum. 2006;55:19-26.

20. Jeon CY, Murray MB. Diabetes mellitus increases the risk of active tuberculosis: a systematic review of 13 observational studies. PLoS Med. 2008;5:e152.

21. Rehm J, Samokhvalov AV, Neuman MG, Room R, Parry C, Lönnroth K, Patra J, Poznyak V, Popova S. The association between alcohol use, alcohol use disorders and tuberculosis (TB). A systematic review. BMC Public Health. 2009;9:450.

22. Maurya V, Vijayan VK, Shah A. Smoking and tuberculosis: an association overlooked. Int J Tuberc Lung Dis. 2002;6(11):942-51.

23. Lonnroth K, Williams BG, Cegielski P, Dye C. A consistent log-linear relationship between tuberculosis incidence and body mass index. Int J Epidemiol. 2010;39:149-55.

24. Comstock GW. How much isoniazid is needed for prevention of tuberculosis among immunocompetent adults? Int J Tuberc Lung Dis. 1999;3(10):847-50.

25. LoBue $P$, Menzies D. Treatment of latent tuberculosis infection: an update. Respirology. 2010;15:603-22.

26. Sterling TR, Villarino ME, Borisov AS, Shang N, Gordin F, Bliven-Sizemore V, Hackman J, Hamilton CD, Menzies $D$, Kerrigan A, Weis SE, Weiner M, Wing D, Conde MB, Bozeman L, Horsburgh CR, Chaisson RE; TB Trials Consortium PREVENT TB Study Team. Three months of rifapentine and isoniazid for latent tuberculosis infection. $\mathrm{N}$ Engl J Med. 2011;365:2155-66.

27. Pease C, Amaratunga KR, Alvarez GG. A shorter treatment regimen for latent tuberculosis infection holds promise for at-risk Canadians. Can Commun Dis Rep. 2017;43(3):67-71. Available from: http://www.phac-aspc.gc.ca/publicat/ccdrrmtc/17vol43/dr-rm43-3-4/ar-02-eng.php.

28. Pai M, Denkinger CM, Kik SV, Rangaka MX, Zwerling A, Oxlade O, Metcalfe JZ, Cattamanchi A, Dowdy DW, Dheda K, Banaei N. Gamma interferon release assays for detection of Mycobacterium tuberculosis infection. Clin Microbiol Rev. 2014;27:3-20.

29. Wallis RS, Pai M, Menzies D, Doherty TM, Walzl G, Perkins MD, Zumla A. Biomarkers and diagnostics for tuberculosis: progress, needs, and translation into practice. Lancet. 2010;375:1920-37.

30. Cattamanchi A, Smith R, Steingart KR, Metcalfe JZ, Date A, Coleman C, Marston BJ, Huang L, Hopewell PC, Pai $M$. Interferon-gamma release assays for the diagnosis of latent tuberculosis infection in HIV-infected individuals: a systematic review and meta-analysis. J Acquir Immune Defic Syndr. 2011;56:230-8.

31. Santin M, Munoz L, Rigau D. Interferon- $\gamma$ release assays for the diagnosis of tuberculosis and tuberculosis infection in HIV-infected adults: a systematic review and meta-analysis. PLoS One. 2012;7:e32482.

32. Ferguson TW, Tangri N, Macdonald $K$, Hiebert $B$, Rigatto C, Sood MM, Shaw S, Lerner B, Xu Y, Mahmud V, Komenda P. The diagnostic accuracy of tests for latent tuberculosis infection in hemodialysis patients: a systematic review and meta-analysis. Transplantation. 2015;99(5):1084-91. Available from: https://www.ncbi.nlm.nih.gov/pubmed/25286055.

33. Hoff ST, Peter JG, Theron G, Pascoe M, Tingskov PN, Aggerbeck H, Kolbus D, Ruhwald M, Andersen P, Dheda K. Sensitivity of C-Tb: a novel RD-1-specific skin test for the diagnosis of tuberculosis infection. Eur Respir J. 2016;47:919-28.

34. Barcellini L, Borroni E, Brown J, Brunetti E, Campisi D, Castellotti PF, Codecasa LR, Cugnata F, Di Serio C, Ferrarese M, Goletti D, Lipman M, Rancoita PM, Russo G, Tadolini M, Vanino V, Cirillo DM. First evaluation of QuantiFERON-TB Gold Plus performance in contact screening. Eur Respir J. 2016; 48(5):1411-9.

35. Chegou NN, Heyckendorf J, Walzl G, Lange C, Ruhwald M. Beyond the IFN- $\gamma$ horizon: biomarkers for immunodiagnosis of infection with Mycobacterium tuberculosis. Eur Respir J. 2014;43:1472-86.

36. Pai M, Schito M. Tuberculosis diagnostics in 2015: landscape, priorities, needs, and prospects. J Infect Dis. 2015;211 Suppl 2:S21-8.

37. Zak DE, Penn-Nicholson A, Scriba TJ, Thompson E, Suliman $\mathrm{S}$, Amon LM, Mahomed H, Erasmus M, Whatney W, Hussey GD, Abrahams D, Kafaar F, Hawkridge T, Verver S, Hughes EJ, Ota M, Sutherland J, Howe R, Dockrell HM, Boom WH, Thiel B, Ottenhoff TH, Mayanja-Kizza H, Crampin AC, Downing K, Hatherill M, Valvo J, Shankar S, Parida SK, Kaufmann SH, Walzl G, Aderem A, Hanekom WA; ACS and GC6-74 cohort study groups. A blood RNA signature for tuberculosis disease risk: a prospective cohort study. Lancet. 2016;387(10035):2312-22.

38. Lönnroth K, Migliori GB, Raviglione MC, Abubakar I, D'Ambrosio L, de Vries G, Diel R, Douglas P, Falzon D, 
Gaudreau MA, Goletti D, LoBue P, Matteelli A, Njoo H, Ochoa EA, Solovic I, Story A, Tayeb T, van der Werf MJ, Weil D, Zellweger JP. Towards TB elimination: an action framework for low-incidence countries. Geneva: World Health Organization; 2014.

39. Lönnroth K, Migliori GB, Abubakar I, D'Ambrosio L, de Vries G, Diel R, Douglas P, Falzon D, Gaudreau MA, Goletti D, González Ochoa ER, LoBue P, Matteelli A, Njoo H, Solovic I, Story A, Tayeb T, van der Werf MJ, Weil D, Zellweger JP, Abdel Aziz M, Al Lawati MR, Aliberti S, Arrazola de Onate W, Barreira D, Bhatia V, Blasi F, Bloom A, Bruchfeld J, Castelli F, Centis R, Chemtob D, Cirillo DM, Colorado A, Dadu A, Dahle UR, De Paoli L, Dias HM, Duarte R, Fattorini L, Gaga M, Getahun H, Glaziou P, Goguadze L, Del Granado M, Haas W, Järvinen A, Kwon GY, Mosca D, Nahid P, Nishikiori N, Noguer I, O'Donnell J, Pace-Asciak A, Pompa MG, Popescu GG, Robalo Cordeiro C, Rønning K, Ruhwald M, Sculier JP, Simunović A, Smith-Palmer A, Sotgiu G, Sulis G, Torres-Duque CA, Umeki K, Uplekar M, van Weezenbeek C, Vasankari T, Vitillo RJ, Voniatis C, Wanlin M, Raviglione MC. Towards TB elimination: an action framework for lowincidence countries. Eur Respir J. 2015;45(4):928-52.

40. Uplekar M, Weil D, Lonnroth $K$, Jaramillo E, Lienhardt C, Dias HM, Falzon D, Floyd K, Gargioni G, Getahun H,
Gilpin C, Glaziou P, Grzemska M, Mirzayev F, Nakatani H, Raviglione M; WHO's Global TB Programme. WHO's new end TB strategy. Lancet. 2015;385:1799-801.

41. Getahun H, Matteelli A, Abubakar I, Aziz MA, Baddeley A, Barreira D, Den Boon S, Borroto Gutierrez SM, Bruchfeld J, Burhan E, Cavalcante S, Cedillos R, Chaisson R, Chee CB, Chesire L, Corbett E, Dara M, Denholm J, de Vries G, Falzon D, Ford N, Gale-Rowe M, Gilpin C, Girardi E, Go UY, Govindasamy D, D Grant A, Grzemska M, Harris R, Horsburgh CR Jr, Ismayilov A, Jaramillo E, Kik S, Kranzer K, Lienhardt C, LoBue P, Lönnroth K, Marks G, Menzies D, Migliori GB, Mosca D, Mukadi YD, Mwinga A, Nelson L, Nishikiori N, Oordt-Speets A, Rangaka MX, Reis A, Rotz L, Sandgren A, Sane Schepisi M, Schunemann HJ, Sharma SK, Sotgiu G, Stagg HR, Sterling TR, Tayeb T, Uplekar M, van der Werf MJ, Vandevelde W, van Kessel F, van't Hoog A, Varma JK, Vezhnina N, Voniatis C, Vonk Noordegraaf-Schouten M, Weil D, Weyer K, Wilkinson RJ, Yoshiyama T, Zellweger JP, Raviglione M. Management of latent Mycobacterium tuberculosis infection: WHO guidelines for low tuberculosis burden countries. Eur Respir J. 2015;46:1563-76.

42. Tuberculosis prevention and control in Canada: a federal framework for action. Ottawa: Public Health Agency of Canada; 2014. p. 1-14. Available from: http://www.phacaspc.gc.ca/tbpc-latb/pubs/tpc-pct/index-eng.php.

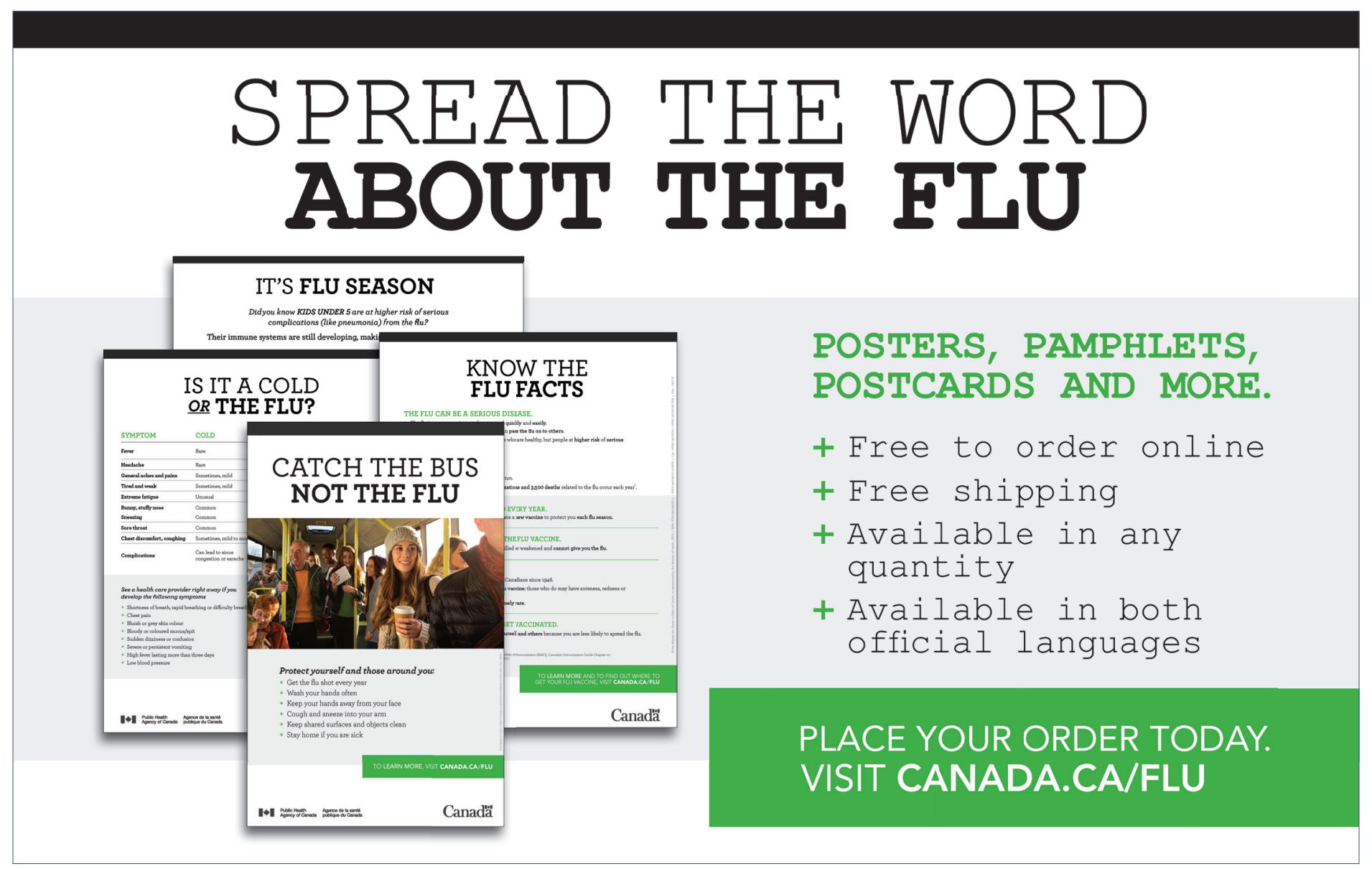

